\title{
Synergising mixture DoE with CFD for ash-slurry optimisation
}

\author{
Subhash Malik and Bikram Jit Singh* \\ Department of Mechanical Engineering, \\ Maharishi Markandeshwar University, \\ Sadopur, Ambala, Haryana, India \\ Email: subhashmalik604@gmail.com \\ Email: chann461@yahoo.com \\ *Corresponding author
}

\begin{abstract}
Present research work describes the issues associated with slurry transportation systems in thermal power plants. It not only explores the importance of such ash handling systems but also embarks upon a step-by-step procedure to optimise slurry contents, without ignoring flow process parameters like velocity and pipe diameter to ensure least possible drop in the flow pressure, along the length of pipe. After analysing the research gaps, a strategic methodology based on the philosophies of mixture design of experiments (DoE) and computational flow dynamics (CFD) was suggested. Experiments were designed and performed in a balanced orthogonal matrix, before simulating through CFD. A deviation of mere $8 \%$ (approximately) was found in the end results, and hence an average drop in pressure from 3176 to $1252 \mathrm{KPa}$ was unleashed, in the first attempt itself. The rheological properties (like $\mathrm{pH}$ value or settling properties) of slurry were assumed to be in required ranges and their relative impacts on critical flow metrics of slurry transportation system were not studied. The present study used an integrated approach to study the flow and further proved its authenticity by implementing it in an Indian thermal power plant successfully.
\end{abstract}

Keywords: bottom ash; CFD; cox-plot; fluent; fly ash; gambit; Minitab; mixture DoE; overlaid contour plot; slurry.

Paper Type: A Case Study.

Reference to this paper should be made as follows: Malik, S. and Singh, B.J. (2016) 'Synergising mixture DoE with CFD for ash-slurry optimisation', Int. J. Experimental Design and Process Optimisation, Vol. 5, Nos. 1/2, pp.68-93.

Biographical notes: Prof. Subhash Malik is an Assistant Professor in Mechanical Engineering Department at Maharishi Markandeshwar University, Sadopur, Ambala, India. He is doing PhD from NIT Kurukshetra in the field of CFD and Reliability. He has done Masters of Technology with distinction in Thermal Engineering from MM University, Mullana. He has performed studies on 'Computational simulation of water and coal ash mixtures through pipeline' for the last 2 years. He had a one-year professional experience as a Junior Engineer Trainee (JET) in Jindal Stainless Limited. 
Dr Bikram Jit Singh is working as a Professor and Head in Mechanical Engineering Department at Maharishi Markandeshwar University, Sadopur, Ambala, India. He has done Masters of Engineering with distinction in Industrial Engineering from Thapar University, Patiala, and received his $\mathrm{PhD}$ from National Institute of Technology, Kurukshetra. He had a three-year professional experience as a Manager in Light Alloy Foundry at Goetze India Limited, a German multinational at Bahadurgarh, India. He had undergone job training on SAP (PP-Module), QS-9000, ISO-TS 16949, SQC Tools and TPM for 2 years. He had worked as Lecturer in Mechanical Engineering Department for 2 years at RIMT-Institute of Engineering \& Technology, Mandi Gobindgarh, India. He was also posted as HOD-Mechanical at BBSBPC, Fatehgarh Sahib, India for one year.

This paper is a revised and expanded version of a paper entitled 'Pressure drop analysis of water and bottom ash mixture flow through straight pipe line with additives', presented at National Conference on Advances in Engineering, Technology and Management (AETM-2015), MMU, Sadopur.

\section{Introduction}

Ash is a major by-product of thermal power plants all over the world. It is an outcome of burning of pulverised coal and is divided into two main categories: fly ash and bottom ash (Usui, Li and Suzuki, 2001). The fly ash particles are too fine that they can be transported from the combustion chamber by exhaust gases themselves (refer Figure 1). They exist in powder form and basically constitute the non-combustible mineral matter in coal (Jaglan, Khanduja and Kaushik, 2013). Fly ash differs from bottom ash in physical, mineralogical and chemical perspectives (Boylu, Dinc,er and Atesok, 2003). Bottom ash is a coarse, granular and incombustible product obtained at the bottom of furnace (see Figure 2). Generally, mixture of solids with liquids is known as slurry (Sarkhi and Solemani, 2004). The physical characteristics of slurry are dependent on many factors such as particle size distribution, solid concentration in the liquid phase, turbulence level, temperature, conduit size and viscosity of the carrier (Harmadi, Machmudah and Winardi, 2002). Actually, slurry is a mixture of solid particles and fluids held in suspension. Water is the most commonly used fluid. The speed of slurry flow should be sufficiently high to maintain the particles in the state of suspension. Slurry transportation through pipeline provides best way to transport ash (Ibrahim, 2005). It causes minimum pollution and is less noisy (Patnaree and Narasingha, 2012). So, this article emphasises more on optimisation of slurry content as well as pipeline dimensions, to improve overall effectiveness and efficiency of transportation. 
Figure 1 Fly ash (see online version for colours)

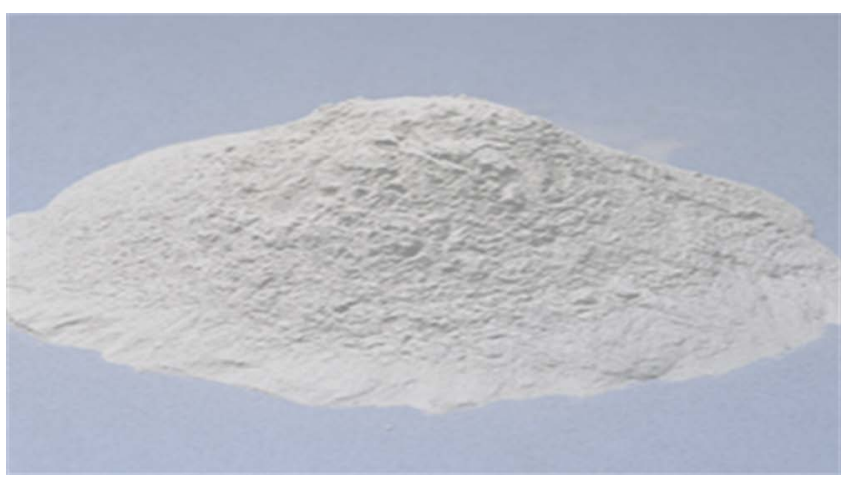

Figure 2 Bottom ash (see online version for colours)

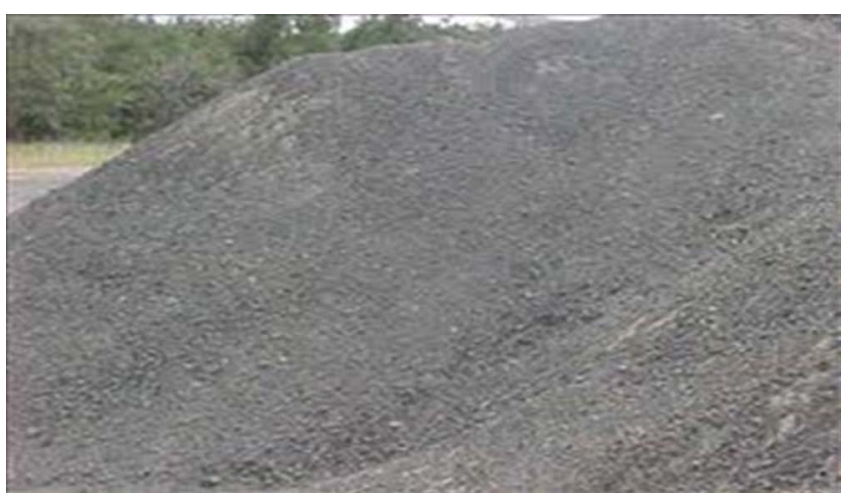

Different types of pipes such as pipes made from carbon steel, cast iron and galvanised iron pipes are being used for transportation of slurry from one point to another. In the present work, carbon steel pipe has been used to transfer slurry from boiler section of plant to the dumping site (Zengjie et al., 2011). Such slurry pipelines have been used to transport solid materials mixed with water for shorter or longer distances. In fact, these pipelines are widely used in many industrial applications for brisk material handling (Verma, Singh and Seshadri, 2006). The slurry is blended with some compound known as 'surfactant' that lowers the surface tension (or interfacial tension) between two liquid particles or between the liquid and solid particles. Detergents, wetting agents, emulsifiers, foaming agents and dispersants can be used as surfactants (Aktas and Woodburn, 2000). For ash slurry, Triton X-100 has been used to reduce interfacial tension in slurry flow. It is realised that slurry system fails mainly due to choking problem in regular operating conditions and this can be avoided substantially by reducing the pressure drop of slurry along the length of pipe. So the pressure drop along the length of pipe becomes the critical metric, which must be monitored and checked while deciding the slurry composition, flow velocity, pipe diameter and so on. 
Experiments at different compositions of fly ash, bottom ash, additive and water are designed through 'Mixture Design of Experiment' technique. Even runs at various settings of flow velocity and pipe diameters have also been carried out. Computational fluid dynamic (CFD) software is used to perform flow analysis for assessing slurry pressure drop inside the pipeline. Initially, the geometry of actual pipe is generated as per its dimensions by using 'Gambit' design tool. Then, the mesh generation of pipe geometry is created that subdivides it into minute control volumes. Meshing is a way to define and break up the whole pipeline into small elements (Goh, 1988). Now each control volume has corresponding values for its flow-dependent variables like velocity and pressure. During pre-processing, boundary conditions are formulated (Mukhtar, Singh and Seshadri, 1994). The simulation is performed at steady-state and the obtained results are visualised post-processing. In the present scenario, a straight pipe is generated to study pressure drop per 100 metre length. Modelling of the pipe is developed in Gambit Software (version 2.2.30), and the next simulation of fluid flow through pipeline is carried out in 'Fluent' software.

Before executing all the designed runs, some extra runs at various compositions have been simulated and validated with actual experimental findings. Now, once simulation is fine-tuned, the CFD software is utilised for systematic accomplishment of all designed runs. Mixture DoE will do the necessary analysis of CFD findings as far as impact of slurry contents, flow velocity and pipe diameter on pressure drop are concerned. This article provides an optimisation approach that not only determines the optimised slurry composition but also provides suitable values of process variables like flow velocity and pipe diameter at which pressure drop would be minimum or within the permissible limits. The two-sample hypothesis testing is applied to verify the solution provided by Minitab calculations. About 30 runs have been conducted at optimised settings and are fed to statistical software for assessing actual accomplishments.

\section{Literature review}

Huge attention has been paid to the topic of easy and safe transportation of slurry since 1996. With time, people have earmarked the hazardous aspects of handling fly and bottom ash. The majority of scholars believe in transporting the ashes and coal dusts by making suitable aqua-based slurry. They found it to be the fastest and environmentalfriendly method to tackle the menace of this fine-grained ash, which may cause fatal diseases like tuberculosis, kidney stones and sever stomach syndromes. Some authors put pressure on nontangible way to transport ash from furnace region. It has been surveyed that the condition in developing nations is even worst and need immediate attention, as ash handling is done manually because of availability of cheaper labour (Sushil, 1990). A wide literature review on slurry transportation system has been conducted to realise the 'status quo' of existing slurry pipeline facilities. An effort has been made to put the philosophies and innovative ways to improve performance metrics of slurry transportation method in a chronological order, as explained in the table below. 
Table 1 Scrutiny of existing work

\begin{tabular}{|c|c|}
\hline References & Work illustrations \\
\hline $\begin{array}{l}\text { Logos and Nguyen } \\
\text { (1996) }\end{array}$ & $\begin{array}{l}\text { The results obtained in this study indicated that, with a careful control } \\
\text { of the particle size distribution, it was possible to prepare optimum } \\
\text { coal-water slurry which had a low viscosity and high solid loadings. }\end{array}$ \\
\hline $\begin{array}{l}\text { Aktas and Woodburn } \\
(2000)\end{array}$ & $\begin{array}{l}\text { This article found that coal and water slurry viscosity was influenced } \\
\text { significantly by surfactant loading, the particle size distribution and the } \\
\text { solid content of coal in water. }\end{array}$ \\
\hline $\begin{array}{l}\text { Usui, Li and Suzuki } \\
\text { (2001) }\end{array}$ & $\begin{array}{l}\text { The work represented a feasibility study of fly ash hydraulic } \\
\text { transportation system with minimum viscosity from a coal-fired power } \\
\text { station to a controlled deposit site which was carried out to predict the } \\
\text { maximum packing volume fraction with non-spherical particles. }\end{array}$ \\
\hline $\begin{array}{l}\text { Harmadi, } \\
\text { Machmudah and } \\
\text { Winardi (2002) }\end{array}$ & $\begin{array}{l}\text { This work studied experimentally the effects of particle size } \\
\text { distribution of pulverised coal to rheology and stability of coal-water } \\
\text { mixture (CWM). Particle size distribution affected the maximum coal } \\
\text { solid concentration achieved in CWM suspension. The results showed } \\
\text { that maximum solid concentration increased with decrease of particle } \\
\text { size. }\end{array}$ \\
\hline $\begin{array}{l}\text { Boylu, Dinc,er and } \\
\text { Atesok (2003) }\end{array}$ & $\begin{array}{l}\text { In this work, three main methods for reducing the frictional pressure } \\
\text { loss were discussed. The first method reduced the degree of flotation of } \\
\text { the particles in the slurry by using suitable chemical additives and } \\
\text { thereby reduced the slurry viscosity. The second method used boundary } \\
\text { liquid such as water, oil and polymer solutions, which were injected at } \\
\text { comparatively small flow rates into the pipe downstream adjacent to } \\
\text { the pipe wall. The third method involved gas injection into the pipe } \\
\text { downstream (from the pump to form a slug flow pattern) which } \\
\text { resulted in substantial frictional pressure loss reductions for a non- } \\
\text { Newtonian slurry. }\end{array}$ \\
\hline $\begin{array}{l}\text { Sarkhi and Solemani } \\
(2004)\end{array}$ & $\begin{array}{l}\text { This work measured the impact of addition of the drag-reducing } \\
\text { polymers (DRP) to two-phase flow patterns in a horizontal } 0.0254-\mathrm{m} \\
\text { pipe. The characteristics of two-phase flow with and without DRP were } \\
\text { described. It was noted that the interfacial shear stress decreased } \\
\text { sharply by adding DRP and the flow pattern map was changed. } \\
\text { Pressure reduction occurred in almost all flow pattern configurations. }\end{array}$ \\
\hline Ibrahim (2005) & $\begin{array}{l}\text { This study explained the new empirical equations for head loss ' } h \text { ' due } \\
\text { to friction undergone by water flowing in a pipeline. The calculation of } \\
\text { the parameters of the proposed models had been done through } \\
\text { nonlinear multivariable regression. Maximum relative errors of each } \\
\text { model were less than } 2 \% \text {. Therefore, these simple equations could offer } \\
\text { vital advantage in optimisation study. }\end{array}$ \\
\hline $\begin{array}{l}\text { Verma, Singh and } \\
\text { Seshadri (2006) }\end{array}$ & $\begin{array}{l}\text { Discussed the rheological behaviour of fly ash slurry with and without } \\
\text { additives for different particle size distributions and concentrations of } \\
\text { the solid-liquid mixture. Sodium hexa-metaphosphate was used at } 0.1 \% \\
\text { concentration (by weight) as additive and the pressure drop in a straight } \\
\text { pipeline of } 75 \mathrm{~mm} \text { diameter was also calculated by using the } \\
\text { rheological data. }\end{array}$ \\
\hline
\end{tabular}


Table 1 Scrutiny of existing work (continued)

\begin{tabular}{ll}
\hline References & Work illustrations \\
\hline Ahmed, Ching and & Investigated the effects of coal characteristics on the properties of coal- \\
Shoukri (2007) & water slurry by using 16 different samples of Chinese coal (from lignite \\
& to anthracite). From the investigation author concluded that the carbon \\
& content and grindability index of coal showed a positive correlation \\
& with the slurry ability. The experiments performed revealed that the \\
& rheological behaviour of CWS could be positively correlated with ash \\
& content.
\end{tabular}

Ekambara et al. Described the internal phase distribution of concurrent air-water bubbly (2008) flow (in a 50.3-mm horizontal pipeline) modelled through CFD. The liquid and gas volumetric superficial velocities varied from 3.8 to 5.1 $\mathrm{m} / \mathrm{s}$ and 0.2 to $1.0 \mathrm{~m} / \mathrm{s}$, respectively.

Naik, Mishra and Defined the design of pipeline to deliver fluid at the required head and Karanam (2009) flow rate in a cost-effective manner. This study presented a computeraided optimisation technique for determination of optimum pipe diameter for a number of idealised turbulent flows.

Chandel, Singh, and Carried out a rheological study for mixture of fly ash and bottom ash Seshadri (2010) slurry. The dependence of relative pressure drop on flow velocity at various concentrations was also analysed. Furthermore, by using the rheological data, pressure drop had been predicted for a straight pipeline of $42 \mathrm{~mm}$ diameter at higher concentrations. Experimental results obtained from a pilot test loop were compared with the predicted results. The comparison showed a very good agreement between these data. Specific energy consumption for the transportation of coal ash slurry was calculated at fixed velocities and its dependence in solid concentration was quantitatively analysed.

Naik, Mishra and Observed the flow characteristics of fly ash slurry at $40 \%$ concentration Karanam (2011) with and without additives after collecting six samples of fly ash from different power stations from South India. They concluded that in this way it was possible to design pipelines and pumping systems for transporting ash slurries at high concentrations.

Chandel (2011) Investigated the slurry flow in a vertical pipe for pressure drop predictions. An axisymmetric model was considered to obtain a steady, incompressible solution of solid-liquid flow in a vertical pipe. Finite volume methodology had been adopted. The Eulerian Multiphase Model in FLUENT 6.1 R was adopted for this work. Mixture $k-€$ turbulence model was used for modelling the turbulence.

Zengjie et al. (2011) Highlighted the effect of ash content and particle size gradation on rheological properties. Author selected two coal samples with corresponding different grinding times and particle sizes. The researcher measured the concentration, viscosity, fluidity and stability of each coal water slurry sample. From the investigations, it was concluded that the ash content in Australian coal was 21.72\% higher than the ash content measured in Chinese coal.

Patnaree et al. (2012) This work examined the impact of particle size distribution and packing characteristics on the rheological behaviour and solid loading of coalwater slurry (CWS). The coal samples with six particle size ranges (i.e., $<38 \mu \mathrm{m}, 38-63 \mu \mathrm{m}, 63-75 \mu \mathrm{m}, 75-90 \mu \mathrm{m}, 90-180 \mu \mathrm{m}$ and $180-250$ $\mu \mathrm{m})$ were used and three different packing characteristics were chosen for the experiments (i.e., mono-modal, bi-modal and multi-modal). The results showed that the coarse-to-fine ratio had an effect on the rheology of CWS. 
Table 1 Scrutiny of existing work (continued)

\begin{tabular}{ll}
\hline References & Work illustrations \\
\hline Kaushal et al. (2012) & $\begin{array}{l}\text { Conducted a numerical simulation of pipeline slurry flow of mono- } \\
\text { dispersed fine particles at high concentration by using Mixture and } \\
\text { Eulerian two-phase models. Both models were an integral part of the } \\
\text { software package FLUENT. It was concluded that the lateral variation } \\
\text { of solid concentration in the pipe cross-section was more dominant at } \\
\text { higher concentrations and flow velocities. }\end{array}$ \\
$\begin{array}{l}\text { Investigated the transition boundaries of different flow patterns for } \\
\text { moderately viscous oil-water two-phase flow through a horizontal } \\
\text { (2013) }\end{array}$ & $\begin{array}{l}\text { pipeline with internal diameter and length of } 0.025 \text { m and 7.16 m, } \\
\text { respectively. Geometry and meshing of the present problem was drawn } \\
\text { by using GAMBIT, and ANSYS FLUENT was used for simulation. A } \\
\text { total of 47,037 quadrilateral elements were chosen for the geometry of } \\
\text { horizontal pipeline. } \\
\text { Used CFD for simulation of two-phase flow in pipe-bends, which were } \\
\text { also subjected to erosion due to liquid or solid particles. The main } \\
\text { objective was to obtain the impact characteristics of the particles upon } \\
\text { the bend, outer wall velocity, angle and frequency of impact. The } \\
\text { influences of some parameters (i.e., particle dimension, particle } \\
\text { and Dupleac (2013) }\end{array}$ \\
\hline
\end{tabular}

Generally, investigators concentrated more on rheological properties of coal, dust, ash and so on to reduce the pressure drop of slurry along the pipeline. However, this has not given a major breakthrough. Mainly, work has been done on the study of slurry flow through pipeline with small diameter and shorter length. The composition of slurry is less focused as far as pressure drop is in picture. Very few scholars have made efforts in this scheme and used the conventional one-factor-at-a-time (OFAT) technique. It is rare to find the work which could optimise contents of slurry by designed and balanced experimental runs, specifically by using Mixture DoE technique. Many authors used simulating software like CFD to save time and energy, but it is hard to see synergy of Mixture DoE with CFD to bring necessary optimisation of slurry composition by taking care of process variables (e.g., flow velocity and pipe diameter) simultaneously.

\section{Proposed methodology}

The present investigation provides an economical slurry flow by minimum use of costly additives and precious water. The rheological properties of slurry are assumed to be favourable and within ranges. The proposed methodology is a unique experimental way to blend various contents of slurry in such a fashion that it ensures minimum possible pressure drop per 100 meter of pipe length. It also elaborates the variation of response at different levels of pipe diameter and flow velocity. It envisages a step-wise approach to use sophisticated Mixture DoE technique for effective slurry optimality (refer Figure 3 for details). Moreover, it is a fact that CFD simulation eases the actual experimentation at various designed conditions appreciably. 
Figure 3 A comprehensive approach for slurry optimisation (see online version for colours)

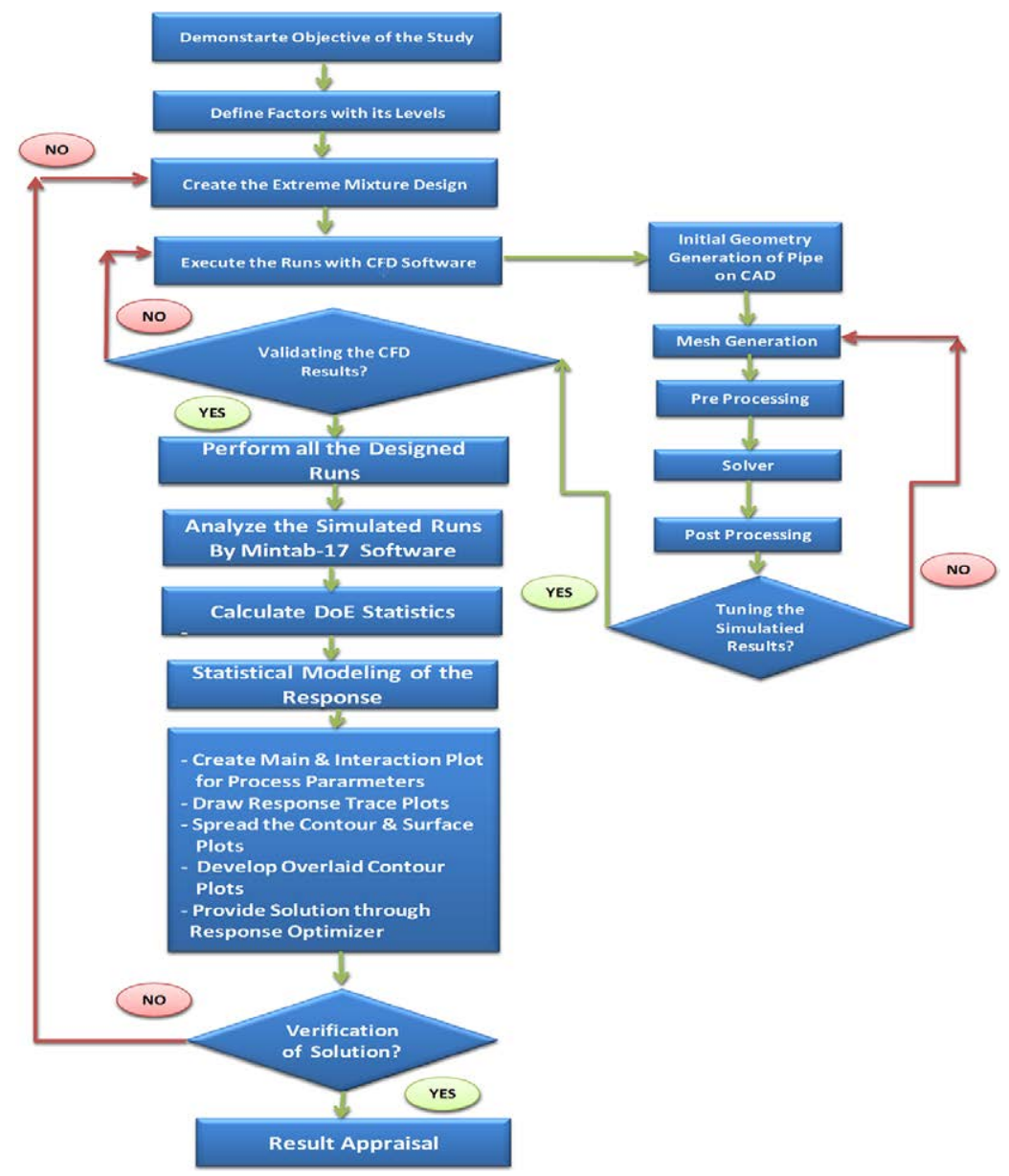

CFD is a branch of fluid mechanics that uses numerical methods and algorithms to analyse and solve problems that involve fluid or slurry flows (Malik, Aggarwal and Dua, 2014). Nowadays it has become an indispensable tool in the design, development, evaluation and refinement of new industrial equipment and flow processes. The use of CFD reduces the development cost of experiments and cuts the time of execution.

\section{Case findings}

An experimental study was conducted in an Indian thermal power plant as per the guidelines of mentioned in the methodology. Initially, the objective was to create an appropriate composition of slurry constituents with relevant values of process parameters, which ensured inherent least pressure drop in slurry flow. After brainstorming with the 
concerned people, factors (or constituents) had been interpreted at their corresponding lower and upper levels (Raisinghani et al., 2005). Two process parameters, namely velocity of slurry flow and diameter of pipe, were shortlisted for studying their respective impact on pressure drop. One linear constraint (regarding bottom ash and fly ash content) was implicated, while designing orthogonal matrix of runs through Mixture DoE.

Table 2 Factors with respective levels

\begin{tabular}{lcccccc}
\hline Factors & $A$ & $B$ & $C$ & $D$ & $P 1$ & $P 2$ \\
\hline Levels & Bottom ash & Fly ash & Additive & Water & Velocity & Pipe diameter \\
Lower & $4 \%$ & $6 \%$ & $1.50 \%$ & $40 \%$ & $25 \mathrm{~m} / \mathrm{s}$ & $350 \mathrm{~mm}$ \\
Upper & $40 \%$ & $50 \%$ & $3 \%$ & $70 \%$ & $40 \mathrm{~m} / \mathrm{s}$ & $450 \mathrm{~mm}$ \\
\hline
\end{tabular}

Linear constraint; $\mathrm{A}+\mathrm{B} \leq 55 \%$

'Minitab-17 Release' software was utilised to generate designed runs by considering principle of multi factor at a time (MFAT) of Mixture DoE. Runs were designed in such a way that the total percentage of constituents in each run remained constant (i.e., 100\%), which varied with the different factors in between their respective levels, along with imposed constraint (Antony, Yao and Ghosh, 2003). Initially, 10 runs were executed in actual environment and their respective pressure drop was calculated with suitable pressure gauges. Now, the same experimental runs were repeated by using CFD as simulating software. After a few minor adjustments, the results of CFD simulation emerged with only less than $4 \%$ error (which was less than the permissible limit of 10\%). Hence, CFD had successfully simulated the real-world experiments along with its environmental and process constraints. After proper validation, all the experimental runs were simulated on CFD at various flow process settings and carried out in the lab itself. About 100 runs had been designed with DoE (refer Annexure 1 for details). These runs at respective experimental settings were performed through CFD simulations. The standardised procedure to organise these runs is described in Table 3.

Table 3 Simulation of experimental runs with CFD (see online version for colours)

Geometry generation

The three-dimensional modelling of a straight pipe was developed in Gambit software version 2.2.30. The geometry was created from the real dimensions and specifications of actual pipe length as shown in the second column of the table.

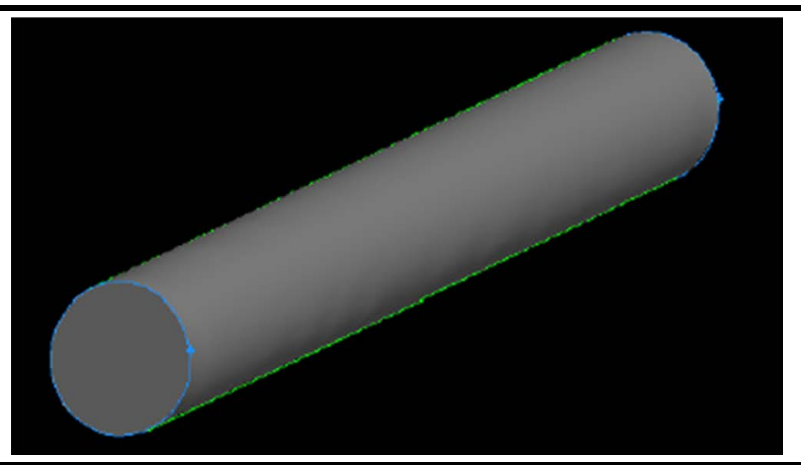


Table 3 Simulation of experimental runs with CFD (see online version for colours) (continued)

\begin{abstract}
Mesh generation
It was the process of subdividing a region (to be modelled) into a set of small control volumes (Joshi and Singh, 2013). In general, a finite element model was defined by a mesh network, which was made up of elements and nodes. Nodes represented points at which features such as displacements were calculated. It was important to check the quality of mesh because parameter such as skewness affected the accuracy of the CFD simulation (Desamala et al., 2013). Each element had a value of skewness between 0 and 1 . The smaller values of equi-angle skew and equi-size skew were more acceptable.
\end{abstract}

\section{Boundary conditions}

The first step in pre-processing was setting up the boundary conditions. Boundary condition will be different for each type of problem. Physically, meaning of boundary condition is to specify the input and output conditions (Nicolici, Prisecaru and Dupleac, 2013). In the present study, velocity was given at the inlet and pressure at the exit of slurry transportation pipeline. Multiphase flow is a flow in which more than one fluid is present. In general, the fluids consist of different chemical species, e.g., solid-water. Two-phase flow of water and coal ash was given as input parameter to simulate the computational fluid dynamic problems (Kaushal et al., 2012). These conditions specify the flow and thermal variables on the boundaries of a physical model. Boundary conditions are therefore a critical component of simulation, and it is important that these are specified logically (Chandel, 2011). It is also important to verify that all of the elements in mesh have positive area/volume ratio; otherwise the simulation in solver is not possible. Basic assumptions on which the simulation was done were as follows (Naik, Mishra and Karanam, 2011):

- Steady-state condition

- Incompressible fluid flow

- Constant fluid properties

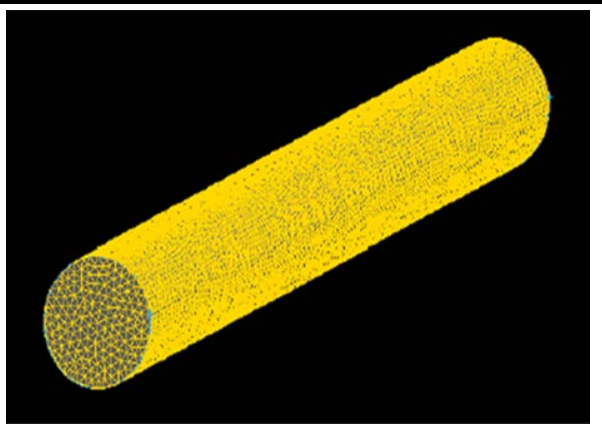

The conditions that were applied for numerical simulation of the slurry transportation line were given below:

- Velocity inlet was applied on the inlet face of pipeline. Pressure outlet was applied on the outlet face of delivery pipeline.

- Slurry was added in material list by giving soot conditions density and molar mass. Bottom ash density and molar mass were taken as $2250 \mathrm{~kg} / \mathrm{m} 3$ and $36.281 \mathrm{~g} / \mathrm{mol}$, respectively. In this case, if fly ash density was taken as 1950 $\mathrm{kg} / \mathrm{m} 3$ then its corresponding molar mass was $28.12 \mathrm{~g} / \mathrm{mol}$.

- Bottom ash's specified diameter was taken as 162 micron and for fly ash it was 57 micron. Simulations were done according to designed run conditions provided by Mixture DoE matrix.

- $4 \%$ turbulence intensity and turbulence viscosity ratio of 10 was taken for inlet conditions. The $4 \%$ backflow turbulence intensity and backflow turbulence viscosity ratio of 10 was taken for outlet condition. 
Table 3 Simulation of experimental runs with CFD (see online version for colours) (continued)

\begin{tabular}{|c|c|}
\hline $\begin{array}{l}\text { Solver } \\
\text { The simulation was started and the } \\
\text { equations were solved iteratively on a } \\
\text { steady-state (Löhner and Camelli, 2005). } \\
\text { There were mainly three methods for } \\
\text { solver: } \\
\text { - Finite volume method (FVM) } \\
\text { - Finite element method (FEM) } \\
\text { - Finite difference method (FDM) } \\
\text { In the finite volume method, governing } \\
\text { equations were in the integral form. In this } \\
\text { method, the solution domain was } \\
\text { subdivided into a finite number of } \\
\text { continuous control volumes (Ekambara } \\
\text { et al., 2008). After this conservation } \\
\text { equation was applied to each control } \\
\text { volume. Computational node was located } \\
\text { at the cancroids of each control volume. } \\
\text { Advantage of this method was that it could } \\
\text { be applied to any types of grids. }\end{array}$ & $\begin{array}{l}\text { In finite element method, governing equations } \\
\text { were multiplied by a weight function before they } \\
\text { were integrated for the entire domain. The finite } \\
\text { element method formulation requires special care } \\
\text { to ensure a conservative solution (Ahmed, Ching } \\
\text { and Shoukri, 2007). This method is more stable } \\
\text { than the finite volume method. Finite difference } \\
\text { method used the governing equations in } \\
\text { differential form. In this method solution domain } \\
\text { was subdivided into grids. This method replaced } \\
\text { the partial derivatives by approximations in terms } \\
\text { of node values of the functions (Fan, Lampinen } \\
\text { and Levy, 2006). One algebraic equation per grid } \\
\text { node was presented. Linear algebraic equation } \\
\text { system was used in this method. Finite difference } \\
\text { could be applied to structural grids (Tralli and } \\
\text { Gaudenzi, 2006). }\end{array}$ \\
\hline $\begin{array}{l}\text { Post-processor } \\
\text { Post-processor is used for the analysis and } \\
\text { visualisation of the obtained results. It } \\
\text { displays the domain geometry and grid } \\
\text { (Logos and Nguyen, 1996). Vectors and } \\
\text { contour plots are used to visualise the } \\
\text { results. The figure in the second column } \\
\text { shows that when the concentration of } \\
\text { bottom ash is increased in slurry then } \\
\text { pressure in the pipe is also increased. The } \\
\text { pressure will increase, when the velocity of } \\
\text { slurry in straight pipe increases. It can be } \\
\text { observed that pressure loss difference at } \\
\text { high velocities is considerably more than } \\
\text { the pressure loss difference at low } \\
\text { velocities. }\end{array}$ & 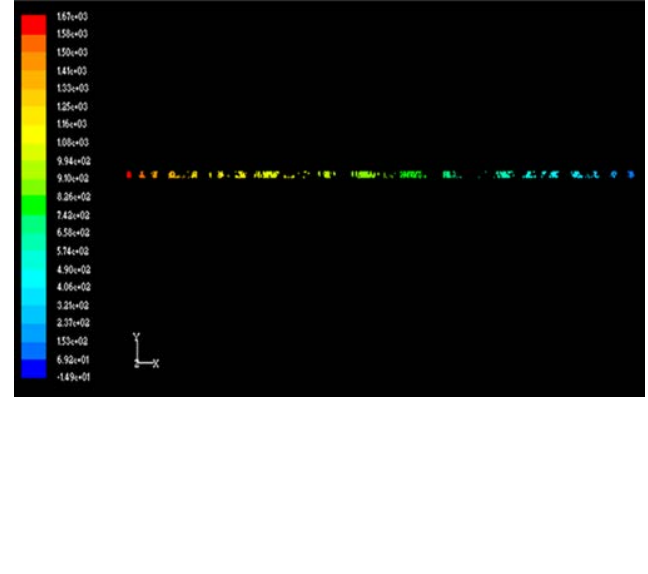 \\
\hline
\end{tabular}

Three-dimensional meshing with double-precision (3-ddp) solver was extremely useful when dealing with very sensitive analyses like aerodynamic drag prediction and multiphase flow systems. Meshing was an important factor to obtain better results. The standard K- $€$ model was selected for pipeline flow simulation. This model gave very useful results for turbulent flow. The convergence criterion in the simulation was $10^{-3}$. The second-order scheme with limiters is one of the most popular numerical scheme due to its accuracy and stability. In CFD, simple algorithm was utilised in the numerical procedure to solve the Navier Stoke's equation, and, hence, it was extensively applied by many researchers to solve different kinds of fluid flow and heat transfer problems. All the designed runs were simulated as per the above procedure, and a proportionate value of 
slurry 'Pressure Drop' along the length of pipe was estimated (see Annexure 1 for details).

Generated runs with response values (pressure drop) were fed into Minitab-17 software for necessary evaluation and analysis. Primarily, data testing was conducted by residual plot to verify the error in predicted regression model of Mixture DoE (look at Figure 4). The normal probability plot ensured that the error was randomly distributed, but scatter plot identified some of the downward trends. This could be ignored because the numbers of runs of response (pressure drop) were more than 30 (sample size was sufficiently large). So it faded away somehow as a chance of systematic error (Narasimhan, 2005).

Figure 4 Residual analysis of response (see online version for colours)

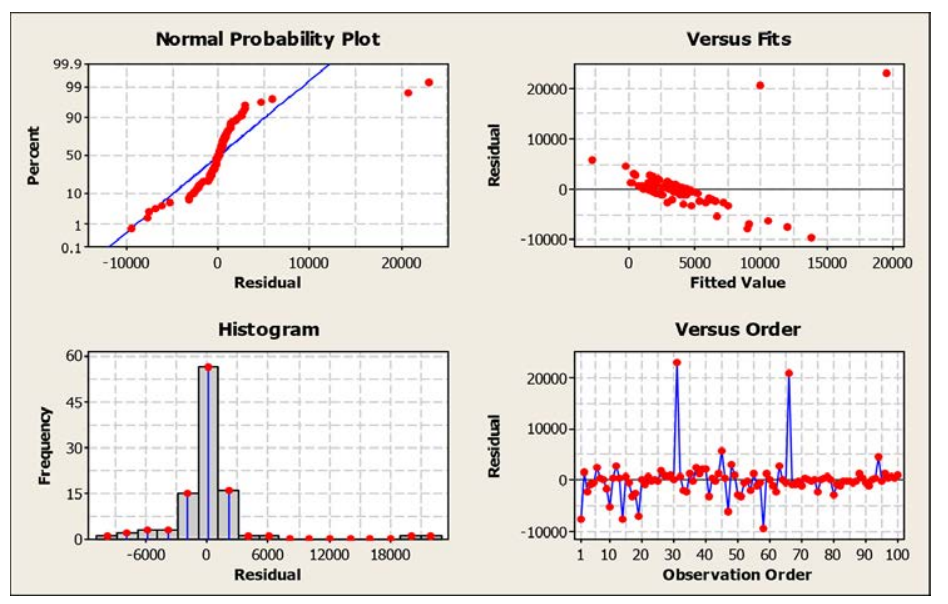

The third graph displayed an almost bell-shaped frequency distribution plot, and the last graph highlighted an arbitrary residue plot around the mean. It implied that the error (or residue) in predicted pressure drop was independent of run occurrence order. Minitab correlated and regressed an equation of pressure drop in terms of slurry contents (i.e., bottom ash, fly ash, additive and water) along with its two-way, three-way interactions and main parameters (i.e., flow velocity and pipe diameter) as quoted below.

Pressure Drop $=-9197$ Bottom Ash - 10918 Fly Ash + 6008

Additive +22605 Water +142848 (Bottom

ash $\times$ Water $)+27694($ Water $\times$ Velocity $)+$

1362719 (Additive $\times$ Water $\times(-)$ Velocity) -

$119(1 /$ Additive $\times$ Velocity $)+133896$

Bottom Ash $\times$ Water $\times(-) 2 \times$ Pipe Diameter

-730580 (Additive $\times$ Water $\times(-) 2 \times$ Pipe Diameter)

The magnitude of coefficients for different factors and factor interactions directly reflected the impact of each on pressure drop. Higher weight signified the higher influence of corresponding factor on the response (Singh and Khanduja, 2011a). From the 
above model, it was obvious that in the present case, water had more effect on pressure drop than fly ash and bottom ash. The sign (positive or negative) of coefficient revealed whether the factor or its interaction was directly or inversely proportional to pressure drop.

The main effect plot of process parameters highlighted the independent repercussions on pressure drop when each factor varied in between its lower and upper levels (see Figure 5). It pin-pointed the regular rise of pressure drop with variation in velocity from $25 \mathrm{~m} / \mathrm{s}$ to $40 \mathrm{~m} / \mathrm{s}$, whereas response decreased when pipe diameter increased from 350 to $450 \mathrm{~mm}$.

Figure 5 Main effect plot for pressure drop (see online version for colours)

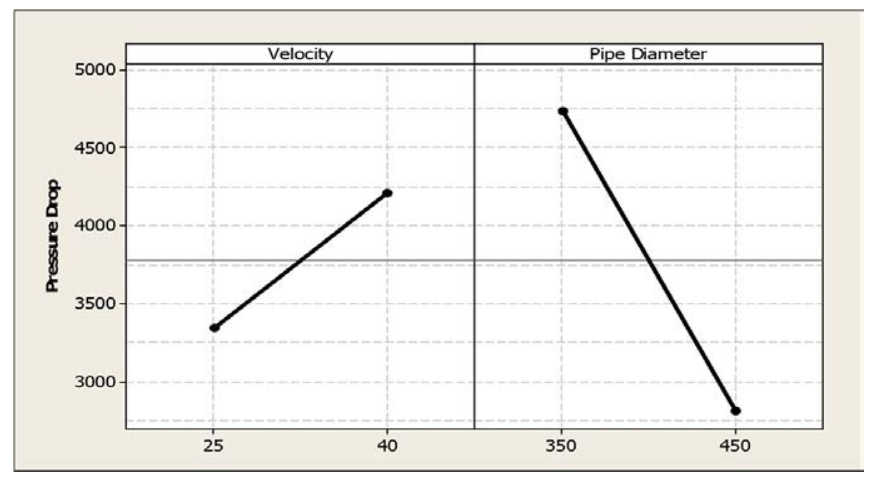

Similarly, behaviour of pressure drop with simultaneous variations in flow velocity and pipe diameter had been drawn through interaction plot for the process parameters (refer Figure 6). While varying the factors concurrently (within their level ranges), the crossed lines revealed the significance of the given interaction, as far as pressure drop was concerned.

Figure 6 Interaction plot of process parameters (see online version for colours)

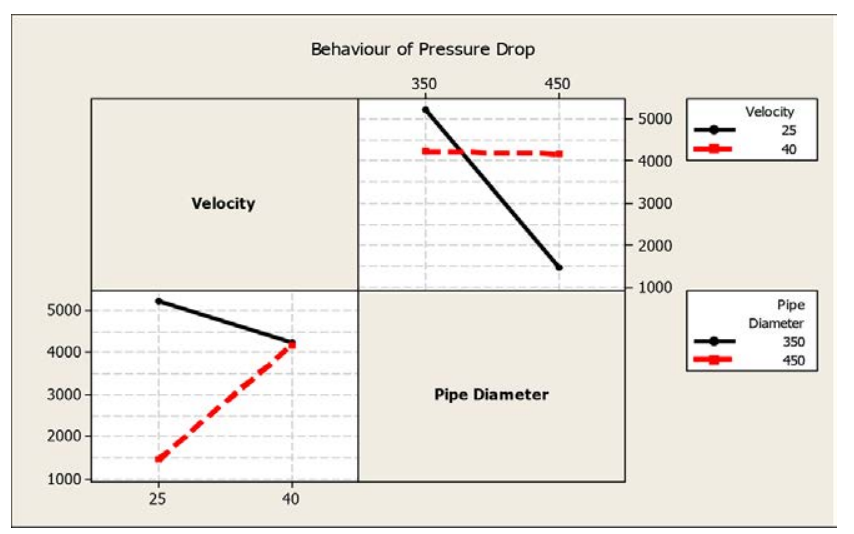

For a deeper insight, a surface plot had been sketched (see Figure 7). Flow velocity was taken on $\mathrm{X}$-axis and corresponding pipe diameter on $\mathrm{Y}$-axis. The whole region of the XY plane was divided suitably into differently coloured sections. Each section earmarked the region of specific pressure drop range. The relative holding values of slurry composition 
was clearly indicated on the side margin. For example, purple colour reflected the region of pressure drop (more than 19500) which was lying relatively closer to the boundaries of pipe diameter from 350 to $375 \mathrm{~mm}$ and velocity variation from 25 to $30 \mathrm{~m} / \mathrm{s}$, respectively.

Figure 7 Surface plot for process parameters (see online version for colours)

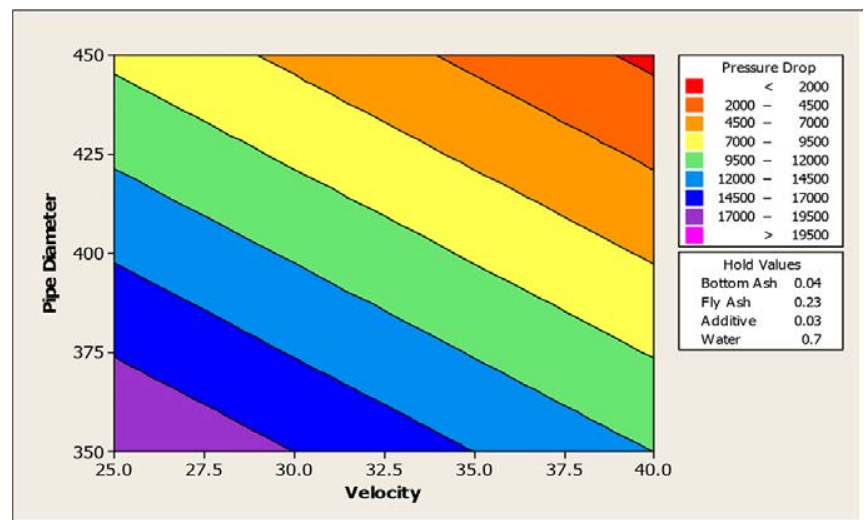

In compliance with the proposed approach, a response trace plot (also called a component effects plot) had been delineated. It showed how each component (or a mixture constituent) affected the response, relative to a reference blend. If the design contained process (or amount) variables then they must be held at a fixed level (look at Figure 8). In the present manifestation, reference blend was presumed and detailed at the margin of Cox plot as below. This ratio of mixture was assumed as a zero setting. Now if we increase or decrease the proportion of any component then pressure drop will vary accordingly and this is being represented here by different coloured lines. For example, if we increased the bottom ash from reference blend (0.1925) then respective pressure drop dipped up to $1400 \mathrm{kPa}$, but it suddenly started rising till $4000 \mathrm{kPa}$ (follow the black curve). Similarly, if water level raised from the reference blend value (i.e., 0.5325 or $53.25 \%$ ) then the pressure drop reached up to $3800 \mathrm{kPa}$. Upon further escalating the additive from 0.0225 (or $2.25 \%$ ), it showed the pressure drop till $4200 \mathrm{kPa}$. The two shortlisted process parameters were maintained at lower levels.

Figure 8 Cox response trace plot (see online version for colours)

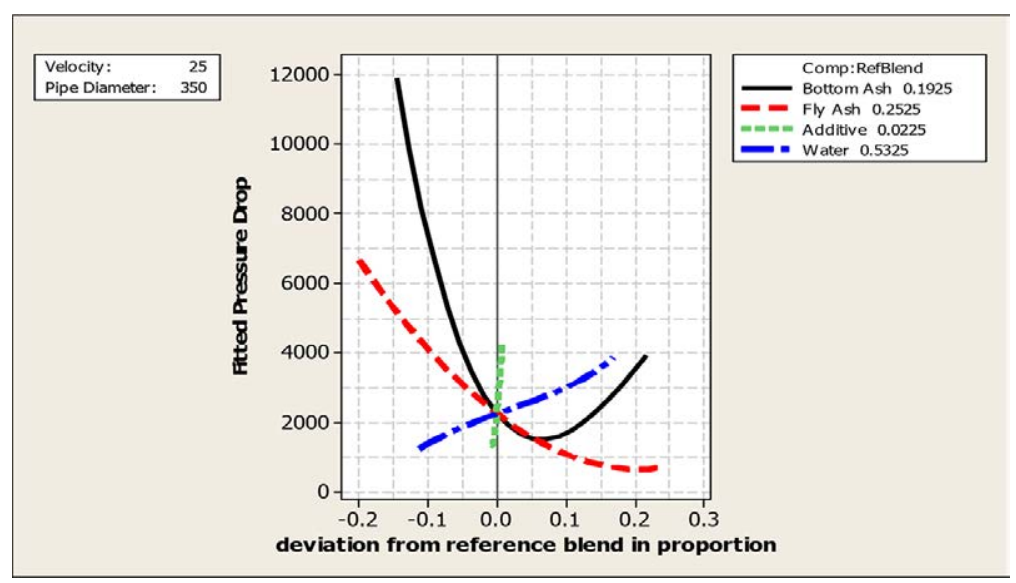


According to the proposed methodology, mixture contour plots had been laid down using a variety of holding combinations of process parameters by taking a reasonable additive value of 0.015 (or 1.5\%). The response variable was related to the three mixture components based on a model equation (refer Figure 9). Those points which had the same response were connected to produce contour lines of constant responses. If you changed the holding levels (or values) then response surface would change as well and sometimes deviate drastically.

Figure 9 Multiple-mixture contour plot for pressure drop (see online version for colours)

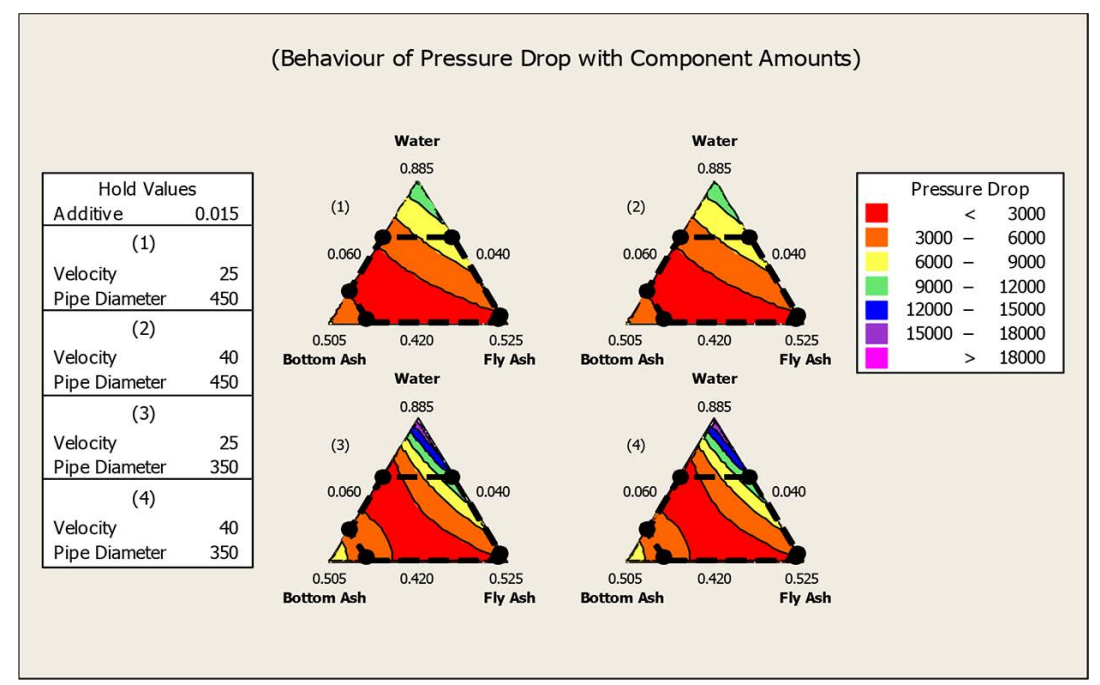

Water, bottom ash and fly ash were the three major constituents in thermal power plant's slurry. The additive percentage was worked out from the Cox plot, and a value of $1.5 \%$ was found sufficient. Now, for lower- and upper-level combinations of flow velocity and pipe diameter, four contour plots had been analysed that elaborated the pressure drop variations comprehensively. Each plot was a combination of set of regions related to specific pressure drop zones like brown zone, which reflected the pressure drop zone from 3000 to $6000 \mathrm{kPa}$, or the red zone, which represented the pressure drop less than $3000 \mathrm{kPa}$.

After studying the main and interaction plot, the velocity was fixed to $40 \mathrm{~m} / \mathrm{s}$, and corresponding pipe diameter was shortlisted as $450 \mathrm{~mm}$, to bring some breakthrough in pressure drop. To materialise the favourable region of response, an overlaid contour plot was sketched out (see Table 4). Each set of contour lines defined the boundaries of acceptable response range which one could impose. As we wanted to reduce the pressure drop, we tried to highlight the region corresponding to pressure drop between 900 to $2500 \mathrm{kPa}$ only. The solid line was the lower bound, and the dotted line represented the upper bound in each contour plot drawn respective to various holding values of factors. It focused on the optimised values of factors to a great extent. The white region was the desired one, which entitled response in its required range. The coordinates of three factors that enclosed this white region could easily be back-tracked. Minitab software draw the plots individually by holding additive at $2.25 \%$, water at $56 \%$, bottom ash at $22 \%$ and fly ash at $28 \%$, sequentially. 
Table 4 Overlaid contour plots (see online version for colours)

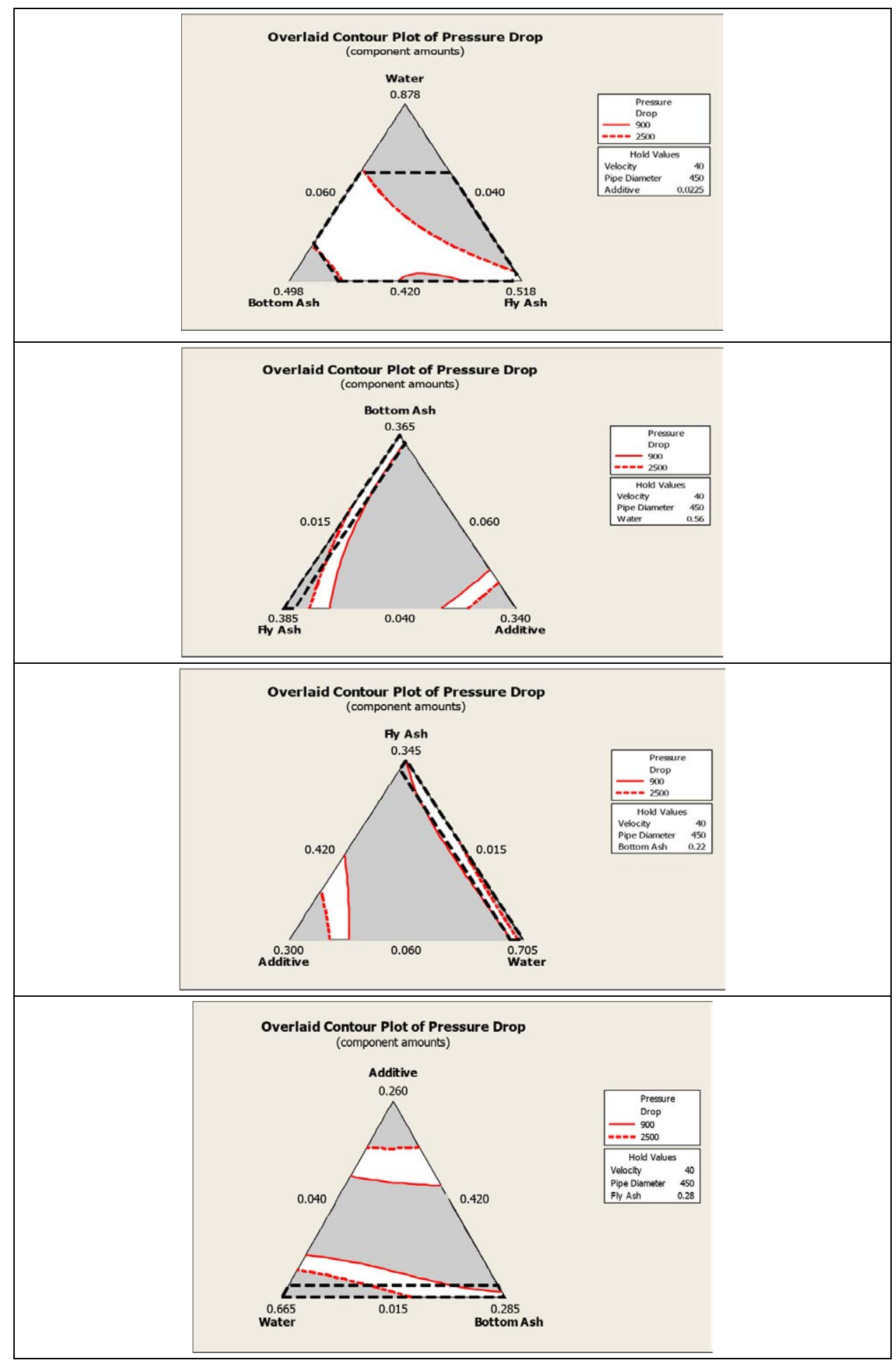


At last, the response optimiser tool of Minitab software was used to predict specific values of slurry components and process parameters at which pressure drop would be least (refer Figure 10). The optimisation plot showed how the factors affected the predicted responses and allowed us to modify the factor settings interactively. Each column of the graph was set to correspond to a factor and the row was dedicated to a response variable. Each cell of the graph showed how the corresponding response variable or composite desirability changed as a function of one of the concerned factor while other factors remained fixed (Singh and Khanduja, 2011b). The numbers displayed in the top row displayed the high and low factor settings in the experimental design, and the readings specified by the red colour were the solutions provided by response optimiser. The first column showed a combined overall desirability of $94.6 \%$ to obtain pressure drop of about $1185.7 \mathrm{kPa}$ (whereas slurry contains $21.99 \%$ bottom ash, $32 \%$ fly ash, $1.78 \%$ additive and water content at $44.23 \%$ ). The flow velocity should be approximately $34 \mathrm{~m} / \mathrm{s}$ and pipe diameter must be near $440 \mathrm{~mm}$. The vertical red lines on the graph represented the current factor settings chosen as a solution to slurry optimisation problem. The horizontal blue lines represented the corresponding response values (Parody and Autin, 2013). The grey regions indicated the factor settings where the corresponding response (pressure drop) has zero desirability.

Figure 10 Response optimiser (see online version for colours)

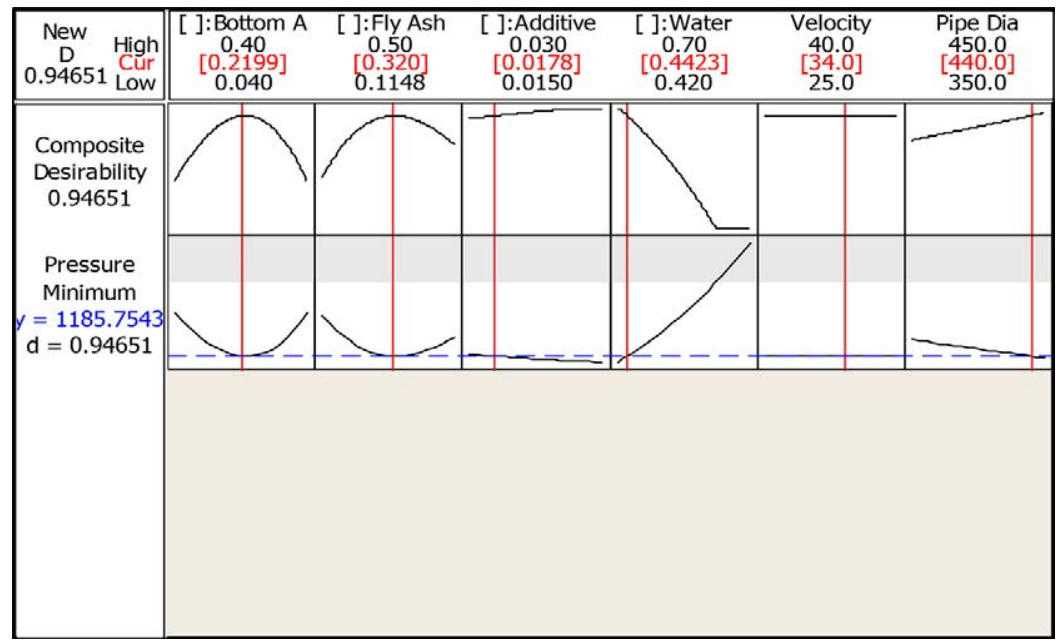

In order to verify the pressure drop achieved from synergy of CFD and Mixture DoE, real-world experimental runs (at least 30 in numbers) had been performed at optimised slurry composition and process parameter values. After that, a two-sample $t$-test was executed on pressure drop data (as shown in Table 5) to check and monitor the actual response value achieved at predicted solution. It also compared the pressure drop at optimised settings appropriately with regular drop in pressure at general settings. The optimised settings (OS) of factor was the specific solution provided by Mini Tab, whereas general settings (GS) of factors were the random values varying in between the respective lower and upper levels of factors. 
Table 5 Pressure drop data at general settings and optimised settings of factors

\begin{tabular}{|c|c|}
\hline Pressure drop (GS) & Pressure drop (OS) \\
\hline 4243.8 & 1345.2 \\
\hline 4243.8 & 1278.9 \\
\hline 2912.3 & 1195.2 \\
\hline 1426.8 & 1352.1 \\
\hline 1084.4 & 1225.4 \\
\hline 1425.1 & 1255.1 \\
\hline 4243.8 & 1320.4 \\
\hline 4243.8 & 1133.7 \\
\hline 1185.2 & 1335.2 \\
\hline 4243.8 & 1159.2 \\
\hline 4243.8 & 1332.4 \\
\hline 4243.8 & 1145.2 \\
\hline 4125.3 & 1175.5 \\
\hline 2103.6 & 1201.5 \\
\hline 3488.4 & 1188.2 \\
\hline 4243.8 & 1195.4 \\
\hline 2489.3 & 1301.5 \\
\hline 2995.5 & 1234.7 \\
\hline 3808.6 & 1255.9 \\
\hline 1424.8 & 1204.2 \\
\hline 4243.8 & 1191.4 \\
\hline 4113.4 & 1298.1 \\
\hline 2674.7 & 1325.1 \\
\hline 4243.8 & 1301.2 \\
\hline 4243.8 & 1288.4 \\
\hline 1502.5 & 1280.4 \\
\hline 4243.8 & 1199.4 \\
\hline 3597.5 & 1208.4 \\
\hline 2987.3 & 1301.4 \\
\hline 994.2 & 1339.3 \\
\hline
\end{tabular}

The required hypothesis was formulated. 'Null hypothesis' favoured no variation in mean pressure drop, whereas 'alternate hypothesis' supported the major variation in pressure drop at respective general and optimised settings. The data procured during the experimentation had been fed to Minitab software for conceiving the two-sample $t$-test and the relevant statistics are illustrated in Figure 11. 
Figure 11 Statistics of two-sample $t$-test

Two-sample $t$-test: pressure drop (GS) vs. pressure drop (OS)

Two-sample $t$-test for pressure drop at general settings and pressure drop at optimised settings

\section{Mean, SD, SE, Mean}

Pressure drop (GS) $303176 \quad 1221 \quad 223$

Pressure drop (OS) $301252.3 \quad 66.1 \quad 12$

Difference $=\mathrm{mu}($ pressure drop $(\mathrm{GS}))-\mathrm{mu}($ pressure drop $(\mathrm{OS}))$

Estimate for difference: 1923

95\% CI for difference: $(1467,2380)$

$T$-test of difference $=0($ vs not $=): T$-Value $=8.61$

$P$-value $=\mathbf{0 . 0 0 0}, d f=29$

As the ' $p$ value' came out to be 0.000 , which was less than the barrier value of 0.05 , the alternate hypothesis had been accepted. Hence, the statistically significant difference between the means of pressure drop at general settings and optimised settings was found to have the $95 \%$ confidence intervals. To verify the results of $t$-test graphically, appropriate individual value plot and box plot should be drawn (Singh and Sodhi, 2014). The first graph was the individual value plot, pinpointing all the pressure drop points independently at general and optimised settings (see Figure 12). The pressure drop mean line showed a negative slope towards optimised settings, which means substantial reduction in mean pressure drop (i.e., from 3175.5 to 1252.2) had been achieved.

Figure 12 Individual and box plot (see online version for colours)

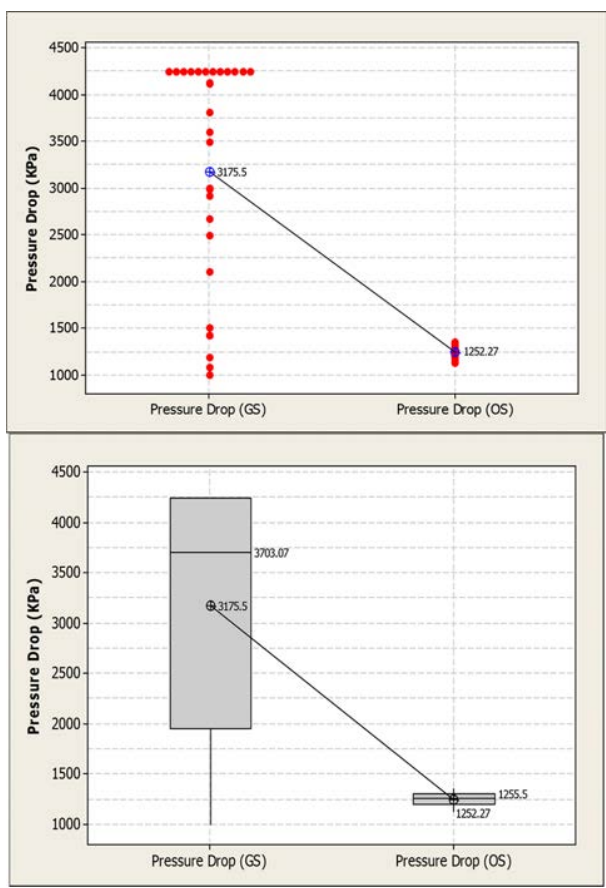


Figure 13 Comparison of Pressure drop at GS \& OS (see online version for colours)

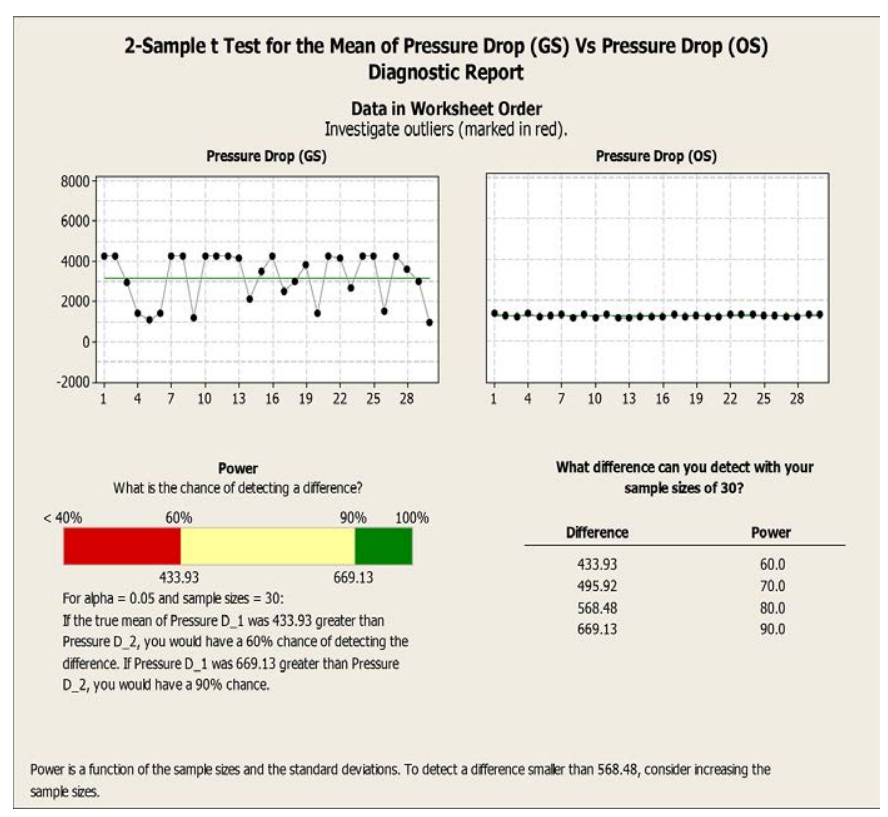

The software predicted an average pressure drop of $1185.7 \mathrm{kPa}$, but in actual terms we obtained a drop of $1252.2 \mathrm{kPa}$. This difference might have occurred due to some noise and uncontrolled elements in actual working conditions. The second graph was the box plot, which demonstrated the non-ignorable gap between mean and median of pressure drop data in general settings than those in optimised settings. This reflected an uncertain or volatile behaviour of slurry flow process in general setting of factors.

A diagnostic report was provided by the software to visualise the pressure drop at general and optimised settings effectively. The control graphs explained in particular the deviation and dissimilitude among pressure drop data at general and optimised settings. The mean pressure drop line at general settings was lying quite higher than the corresponding mean pressure drop line at optimised settings. Hence, this was supporting our findings. Moreover, this report also depicted $60 \%$ probability of getting difference of $433.9 \mathrm{kPa}$ in between pressure drop at GS and OS, respectively. Similarly, it also predicted in advance how the chance of getting the difference increases (from 60 to 90\%) with relative rise in difference of pressure drop (from 433.9 to $669.1 \mathrm{kPa}$ ) as far as GS and OS are concerned.

Finally, a summary report encapsulated the whole findings and illustrated the substantial decrease in mean and standard deviation of pressure drop at GS and OS statistically (refer Figure 14). Normal distribution curves before and after optimisations were self-explaining the achievements along with the hike of 1.35 in flow process performance index (Ppk). The decrease in standard deviation $(-1155.0)$ further inculcated more consistency and repeatability in slurry flow process among longer pipes. 
Figure 14 Summary report (see online version for colours)

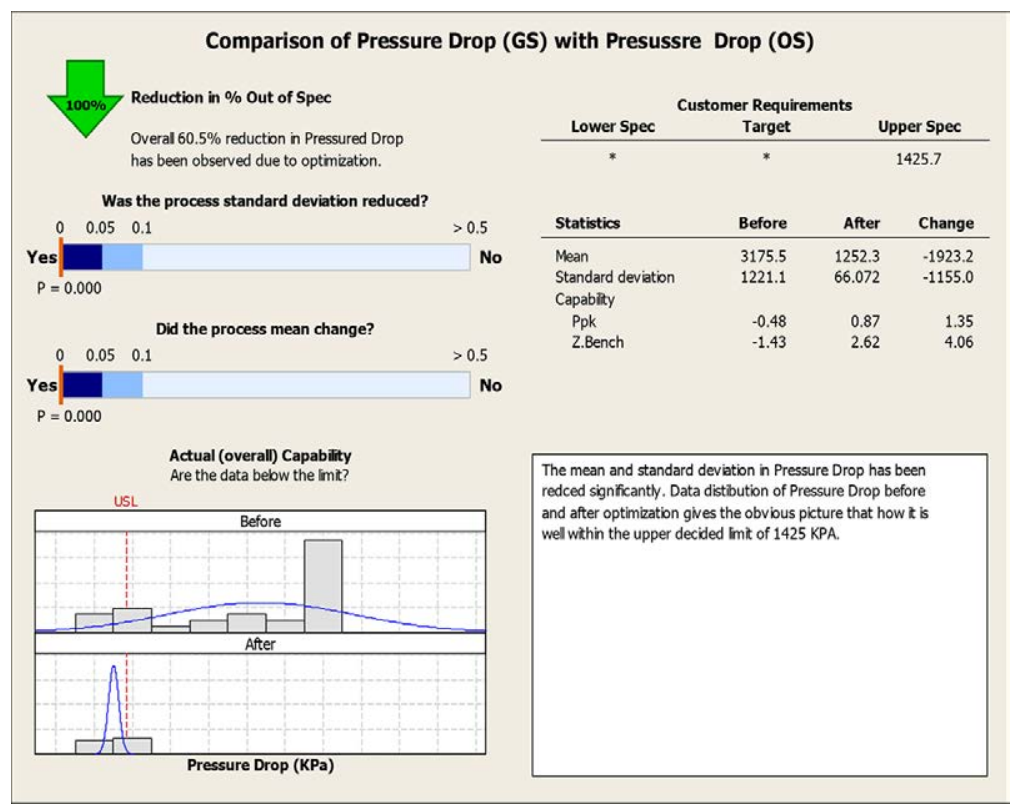

More than $95 \%$ of pressure drop data (at optimised settings) was falling behind the upper limit of $1425 \mathrm{kPa}$, and this proved the efficacy of the proposed approach. An overall reduction of $60.5 \%$ in pressure drop had been attained through this comprehensive methodology, which used the application of Mixture DoE and CFD principles, strategically.

\section{Conclusion}

The problem of ash handling is mounting day by day in thermal power plants, specifically in developing nations. The literature review stresses the flushing of bottom and fly ash through mixture of water and additives, since it is emerging as a most economical and green way to accomplish this difficult job. Pressure drop along the length of pipe has now emerged as a critical performance metric, which can cause choking or even death for personnel involved in such transportation systems. The rheological properties of ash-slurry ensures smooth flow but only up to some extent. In the above study, we assumed controlled ranges of rheological properties of slurry, but it still needs a lot of improvement and input to decrease the pressure drop sufficiently. This work emphasises the optimisation of slurry composition and flow process parameters to tackle this erratic problem of severe pressure drop along the pipe lengths. The methodology proposed in this article has been devised by taking care of the fact that shear stress within the slurry increases with rise in concentration of bottom and fly ash along with various combinations of flow velocities and pipe diameters. This integrated approach will involve the advantages of Mixture DoE and CFD, simultaneously. The designed experiments are better than hit-and-trial runs and have the capability to utilise the effect of multiple factors at a time. Further runs are simulated with CFD, which trims the effort, energy and 
time remarkably. The results have been analysed through Minitab statistical software to deduce logical inferences. The optimised solution provided by tab is further verified by conducting some pilot runs. A two-sample $t$-test has been applied and the test predicted reduction in pressure drop from 3176 to $1252 \mathrm{kPa}$, with $95 \%$ confidence level. Approximately $60 \%$ cutback in pressure drop has been effectuated in a single attempt, which is quite remarkable and opens new doors for its scope in future. Thermal plant engineers and practitioners can use this exhaustive approach to bring breakthroughs in their already-installed ash-slurry transportation systems or can also design a new system. CFD application gives freedom to simulate runs with different compositions of various contents along with different process parameters. Like in some plants, only bottom ash is flushed out by slurry transportation system because of having independent fly ash arresters with corresponding disposal system. Any number of constituents with feasible levels of presence can be simulated through CFD. Flow process parameters like pipe material, viscosity, discharge and impact of different additives can also be studied efficiently through this noteworthy methodology.

\section{References}

Ahmed, W.H., Ching, C.Y. and Shoukri, M. (2007) 'Pressure recovery of two-phase flow across sudden expansions', International Journal of Multiphase Flow, Vol. 33, No. 6, pp.575-594.

Aktas, Z. and Woodburn, E.T. (2000) 'Effect of addition of surface active agent on the viscosity of a high concentration slurry of a low-rank British coal in water', Fuel Processing Technology, Vol. 62, No. 1, pp.1-15.

Antony, J., Yao, T. C. and Ghosh, S. (2003) 'Training for design of experiments', Work Study, Vol. 52, No. 7, pp.341-346.

Boylu, F., Dinc,er, H. and Atesok, G. (2003) 'Effect of coal particle size distribution, volume fraction and rank on the reheology of coal-water slurries', Fuel Processing Technology, Vol. 85, No. 4, pp.241-250.

Chandel, S. (2011) 'Axi-symmetric slurry flow prediction in a vertical pipe', The 11th Asian International Conference on Fluid Machinery, I.I.T. Madras.

Chandel, S., Singh, S. N. and Seshadri, V. (2010) 'Transportation of high concentration coal ash slurries through pipelines', International Archive of Applied Sciences and Technology, Vol. 1, No. 1, pp.1-9.

Desamala, A. B., Dasari, A., Vijayan, V., Bharath, K., Goshika, Dasmahapatra, A. K. and Mandal, T. K. (2013) 'CFD simulation and validation of flow pattern transition boundaries during moderately viscous oil-water two-phase flow through horizontal pipeline', International Journal Multiphase Flow, Vol. 27, No. 5, pp.885-910.

Ekambara, K., Sanders, R.S., Nandakumar, K. and Masliyah, J.H. (2008) 'CFD simulation of bubbly two-phase flow in horizontal pipes’, Chemical Engineering Journal, Vol. 144, No. 2, pp.277-288.

Fan, H.Y., Lampinen, J. and Levy, Y. (2006) 'An easy to implement differential evolution approach for multiobjective optimizations', Engineering Computations, Vol. 23, No. 2, pp.124-138.

Goh, T. N. (1988) 'Statistical methodologies for quality and production improvement', Industrial Management \& Data Systems, Vol. 88, No. 9-10, pp.21-24.

Harmadi, E., Machmudah, S.S. and Winardi, S. (2002) 'Effect of particle size distribution on rheology and stability of high Concentration Coal-Water Mixture (CWM) with Indonesian low rank coal', Jurnalteknikmesin, Vol. 2, No. 1, pp.3-98.

Ibrahim, C. (2005) 'Simplified equations calculate head losses in commercial pipes', The Journal of American Science, Vol. 1, No. 1, pp.1-3. 
Jaglan, P., Khanduja, D. and Kaushik, P. (2013) 'Capacity waste at thermal power plants in India: a six sigma perception', International Journal of Six Sigma and Competitive Advantage, Vol. 8, No. 1, pp.22-33.

Joshi, R. and Singh, B.J. (2013) 'Operational management of a centrifugal slurry pump through strategic CFD Modeling', International Journal of Modelling in Operations Management, Vol. 3, Nos. 3-4, pp.241-266.

Kaushal, D.R., Thinglas, T., Tomita, Y., Kuchii, S. and Tsukamoto, H. (2012) 'CFD modeling for pipeline flow of fine particles at high concentration', International Journal of Multiphase Flow, Vol. 43, No. 1, pp.85-100.

Logos, C. and Nguyen, Q.D. (1996) 'Effect of particle size on the flow properties of South Austriala coal water slurry', Power Technology, Vol. 88, No. 1, pp.55-58.

Löhner, R. and Camelli, F. (2005) 'Optimal placement of sensors for contaminant detection based on detailed 3D CFD simulations', Engineering Computations, Vol. 22, No. 3, pp.260-273.

Malik, S., Aggarwal, L. and Dua, A. (2014) 'Pressure drop analysis of water and fly ash mixture flow through straight pipeline', International Journal of Engineering Research and Applications, National Conference on Advances in Engineering and Technology, pp.17-20.

Mukhtar, A., Singh, S.N. and Seshadri, V. (1994) 'Pressure drop in a long radius $90^{\circ}$ horizontal bend for the flow of multisided heterogeneous slurry', International Journal Multiphase Flow, Vol. 21, No. 2, pp.329-334.

Naik, H.K., Mishra, M. K. and Karanam, R. (2009) 'Rheological characteristic of fly ash slurry at varying temperature environment with and without additive', World of Coal Ash Conference, Lexington, $K Y, U S A$.

Naik, H.K, Mishra, M. K. and Karanam, R. (2011) 'Evaluation of flow characteristics of fly ash slurry at $40 \%$ solid concentration with and without an additive', World of Coal Ash Conference in Denver, CO, USA.

Narasimhan, K. (2005) 'Design of Experiments with Minitab', The TQM Magazine, Vol. 17, No. 2, pp.208-209.

Nicolici, S., Prisecaru, I. and Dupleac, D. (2013) 'Two-phase flow CFD modeling for evaluation of particulate erosion', U.P.B. Scientific Bulletin, Series D, Vol. 75, No. 2, pp.1-3.

Parody, R. and Autin, M. (2013) 'Confident visualization techniques in the analysis of mixture experiments', International Journal of Experimental Design and Process Optimisation, Vol. 3 , No. 3, pp.245-262.

Patnaree, B. and Narasingha, H. (2012) 'Effect of particle size distribution and packing characteristics on the preparation of highly-loaded coal water slurry', International Journal of Chemical Engineering and Applications, Vol. 3, No. 3, pp.1-7.

Raisinghani, M. S., Ette, H., Pierce, R., Cannon, G. and Daripaly, P. (2005) 'Six sigma: concepts, tools, and applications', Industrial Management \& Data Systems, Vol. 105, No. 4, pp.491-505.

Sarkhi, A. Al. and Solemani, A. (2004) 'Effect of drag reducing polymers on two-phase gas -liquid flows in a horizontal pipe', Chemical Engineering Research and Design, Vol. 82, No. 11, pp.1583-1588.

Singh, B.J. and Khanduja, D. (2011a) 'Does analysis matter in six sigma? A case study', International Journal of Data Analysis Techniques and Strategies, Vol. 3, No. 3, pp.300-324.

Singh, B.J. and Khanduja, D. (2011b) 'Introduce quality processes through DOE: a case study in die casting foundry', International Journal of Productivity and Quality Management, Vol. 8, No. 4, pp.373-397.

Singh, B.J. and Sodhi, H.S. (2014) 'Parametric optimization of CNC turning for Al-7020 with RSM', International Journal of Operational Research, Vol. 20, No. 2, pp.180-206.

Sushil, (1990) 'Waste management: a systems perspective', Industrial Management \& Data Systems, Vol. 90, No. 5, pp.1-67.

Tralli, A. and Gaudenzi, P. (2006),'FEM simulation of non-stationary incompressible viscous fluids', Engineering Computations, Vol. 23, No. 8, pp.922-932. 
Usui, H., Li, L. and Suzuki, H. (2001) 'Rheology and pipeline transportation of dense fly ash-water slurry', Korea-Australia Rheology Journal, Vol. 13, No. 1, pp.47-54.

Verma, A.K., Singh, S.N. and Seshadri, V. (2006) 'Pressure drop for high concentration solidliquid mixture across $90^{\circ}$ horizontal circular pipe bend', Indian Journal of Engineering \& Material Sciences, Vol. 13, No. 6, pp.477-483.

Zengjie, Y., Guoguang, W., Xianliang, M., Yuliang, Z., Frank, S., Yaqun, H. and Xiaoqiang, L. (2011) 'A comparative investigation of the properties of coal-water slurries prepared from Australia and Shenhua coals', Mining Science and Technology (China), Vol. 21, No. 3, pp.343-347.

\section{Annexure 1}

\section{Designed experiments of slurry}

\begin{tabular}{|c|c|c|c|c|c|c|c|}
\hline Runs & $\begin{array}{c}\text { Bottom } \\
\text { ash }\end{array}$ & Fly ash & Additive & Water & Velocity & $\begin{array}{c}\text { Pipe } \\
\text { diameter }\end{array}$ & $\begin{array}{c}\text { Pressure } \\
\text { drop } \\
(k P a)\end{array}$ \\
\hline 1 & 0.04 & 0.23 & 0.03 & 0.70 & 40 & 350 & 4243.8 \\
\hline 2 & 0.05 & 0.50 & 0.02 & 0.44 & 25 & 350 & 4243.8 \\
\hline 3 & 0.23 & 0.06 & 0.02 & 0.70 & 40 & 450 & 2912.3 \\
\hline 4 & 0.04 & 0.50 & 0.02 & 0.45 & 25 & 450 & 1426.8 \\
\hline 5 & 0.21 & 0.16 & 0.02 & 0.62 & 25 & 450 & 1084.4 \\
\hline 6 & 0.30 & 0.16 & 0.02 & 0.53 & 25 & 350 & 4243.8 \\
\hline 7 & 0.30 & 0.20 & 0.03 & 0.48 & 25 & 350 & 2845.9 \\
\hline 8 & 0.40 & 0.15 & 0.03 & 0.42 & 25 & 450 & 1477.1 \\
\hline 9 & 0.40 & 0.06 & 0.02 & 0.53 & 40 & 350 & 4243.8 \\
\hline 10 & 0.04 & 0.25 & 0.02 & 0.70 & 25 & 450 & 1193.2 \\
\hline 11 & 0.04 & 0.50 & 0.03 & 0.43 & 25 & 450 & 1425.1 \\
\hline 12 & 0.21 & 0.06 & 0.03 & 0.70 & 40 & 350 & 4243.8 \\
\hline 13 & 0.40 & 0.06 & 0.02 & 0.53 & 25 & 350 & 4243.8 \\
\hline 14 & 0.04 & 0.23 & 0.03 & 0.70 & 25 & 450 & 1185.2 \\
\hline 15 & 0.05 & 0.50 & 0.02 & 0.44 & 40 & 350 & 4243.8 \\
\hline 16 & 0.12 & 0.38 & 0.02 & 0.49 & 40 & 350 & 4243.8 \\
\hline 17 & 0.12 & 0.24 & 0.03 & 0.62 & 25 & 350 & 4243.8 \\
\hline 18 & 0.12 & 0.38 & 0.03 & 0.48 & 40 & 450 & 297.5 \\
\hline 19 & 0.21 & 0.06 & 0.03 & 0.70 & 25 & 350 & 2103.6 \\
\hline 20 & 0.19 & 0.25 & 0.02 & 0.54 & 40 & 450 & 3196.7 \\
\hline 21 & 0.05 & 0.50 & 0.02 & 0.44 & 25 & 450 & 1211.8 \\
\hline 22 & 0.04 & 0.50 & 0.03 & 0.43 & 40 & 450 & 3482.6 \\
\hline 23 & 0.04 & 0.50 & 0.02 & 0.45 & 40 & 450 & 3105.0 \\
\hline 24 & 0.12 & 0.24 & 0.03 & 0.62 & 40 & 450 & 3196.2 \\
\hline 25 & 0.30 & 0.16 & 0.02 & 0.53 & 40 & 350 & 4243.8 \\
\hline
\end{tabular}


Designed experiments of slurry (continued)

\begin{tabular}{|c|c|c|c|c|c|c|c|}
\hline Runs & Bottom ash & Fly ash & Additive & Water & Velocity & $\begin{array}{c}\text { Pipe } \\
\text { diameter }\end{array}$ & $\begin{array}{c}\text { Pressure } \\
\text { drop }(k P a)\end{array}$ \\
\hline 26 & 0.30 & 0.16 & 0.03 & 0.52 & 40 & 450 & 3488.4 \\
\hline 27 & 0.30 & 0.16 & 0.03 & 0.52 & 25 & 350 & 4243.8 \\
\hline 28 & 0.12 & 0.38 & 0.02 & 0.49 & 25 & 350 & 2489.3 \\
\hline 29 & 0.40 & 0.06 & 0.03 & 0.51 & 40 & 450 & 2995.5 \\
\hline 30 & 0.40 & 0.06 & 0.02 & 0.53 & 40 & 450 & 3808.6 \\
\hline 31 & 0.04 & 0.23 & 0.03 & 0.70 & 25 & 350 & 42473.8 \\
\hline 32 & 0.05 & 0.50 & 0.03 & 0.42 & 25 & 450 & 1424.8 \\
\hline 33 & 0.40 & 0.15 & 0.03 & 0.42 & 40 & 350 & 4243.8 \\
\hline 34 & 0.12 & 0.25 & 0.02 & 0.62 & 25 & 450 & 1018.0 \\
\hline 35 & 0.20 & 0.16 & 0.03 & 0.62 & 40 & 450 & 2674.7 \\
\hline 36 & 0.12 & 0.38 & 0.03 & 0.48 & 40 & 350 & 4243.8 \\
\hline 37 & 0.30 & 0.20 & 0.02 & 0.49 & 25 & 350 & 4243.8 \\
\hline 38 & 0.30 & 0.20 & 0.03 & 0.48 & 25 & 450 & 1502.5 \\
\hline 39 & 0.12 & 0.38 & 0.02 & 0.49 & 25 & 350 & 4243.8 \\
\hline 40 & 0.19 & 0.25 & 0.02 & 0.54 & 25 & 350 & 4243.8 \\
\hline 41 & 0.21 & 0.06 & 0.03 & 0.70 & 25 & 450 & 1446.5 \\
\hline 42 & 0.05 & 0.50 & 0.02 & 0.44 & 40 & 450 & 3132.7 \\
\hline 43 & 0.12 & 0.25 & 0.02 & 0.62 & 25 & 350 & 4243.8 \\
\hline 44 & 0.30 & 0.20 & 0.02 & 0.49 & 25 & 450 & 1450.5 \\
\hline 45 & 0.21 & 0.06 & 0.03 & 0.70 & 40 & 450 & 2926.5 \\
\hline 46 & 0.05 & 0.50 & 0.03 & 0.42 & 40 & 450 & 2973.0 \\
\hline 47 & 0.04 & 0.25 & 0.02 & 0.70 & 25 & 350 & 4243.8 \\
\hline 48 & 0.30 & 0.16 & 0.02 & 0.53 & 25 & 450 & 3214.7 \\
\hline 49 & 0.30 & 0.20 & 0.02 & 0.49 & 40 & 450 & 3597.5 \\
\hline 50 & 0.12 & 0.25 & 0.02 & 0.62 & 40 & 450 & 2987.3 \\
\hline 51 & 0.12 & 0.24 & 0.03 & 0.62 & 25 & 450 & 994.2 \\
\hline 52 & 0.20 & 0.16 & 0.03 & 0.62 & 25 & 350 & 4243.8 \\
\hline 53 & 0.21 & 0.16 & 0.02 & 0.62 & 40 & 350 & 4243.8 \\
\hline 54 & 0.40 & 0.06 & 0.03 & 0.51 & 25 & 350 & 4243.8 \\
\hline 55 & 0.21 & 0.16 & 0.02 & 0.62 & 25 & 350 & 2961.5 \\
\hline 56 & 0.21 & 0.16 & 0.02 & 0.62 & 40 & 450 & 2977.3 \\
\hline 57 & 0.12 & 0.38 & 0.03 & 0.48 & 40 & 350 & 4243.8 \\
\hline 58 & 0.04 & 0.25 & 0.02 & 0.70 & 40 & 350 & 4243.8 \\
\hline 59 & 0.23 & 0.06 & 0.02 & 0.70 & 40 & 350 & 4243.8 \\
\hline 60 & 0.12 & 0.38 & 0.03 & 0.48 & 25 & 450 & 1238.8 \\
\hline 61 & 0.12 & 0.38 & 0.02 & 0.49 & 40 & 450 & 2777.1 \\
\hline 62 & 0.12 & 0.24 & 0.03 & 0.62 & 40 & 350 & 4243.8 \\
\hline 63 & 0.30 & 0.16 & 0.03 & 0.52 & 25 & 450 & 3317.5 \\
\hline
\end{tabular}


Designed experiments of slurry (continued)

\begin{tabular}{|c|c|c|c|c|c|c|c|}
\hline Runs & Bottom ash & Fly ash & Additive & Water & Velocity & $\begin{array}{c}\text { Pipe } \\
\text { diameter }\end{array}$ & $\begin{array}{c}\text { Pressure } \\
\text { drop }(k P a)\end{array}$ \\
\hline 64 & 0.12 & 0.38 & 0.02 & 0.49 & 25 & 450 & 1221.6 \\
\hline 65 & 0.40 & 0.15 & 0.02 & 0.44 & 40 & 350 & 4243.8 \\
\hline 66 & 0.04 & 0.25 & 0.02 & 0.70 & 40 & 450 & 30557.1 \\
\hline 67 & 0.04 & 0.50 & 0.03 & 0.43 & 40 & 350 & 4243.8 \\
\hline 68 & 0.12 & 0.38 & 0.02 & 0.49 & 40 & 450 & 2777.1 \\
\hline 69 & 0.19 & 0.25 & 0.02 & 0.54 & 40 & 350 & 4243.8 \\
\hline 70 & 0.20 & 0.16 & 0.03 & 0.62 & 25 & 450 & 1301.8 \\
\hline 71 & 0.12 & 0.38 & 0.03 & 0.48 & 25 & 350 & 3149.8 \\
\hline 72 & 0.40 & 0.15 & 0.02 & 0.44 & 25 & 350 & 4243.8 \\
\hline 73 & 0.04 & 0.50 & 0.02 & 0.45 & 25 & 350 & 3092.4 \\
\hline 74 & 0.12 & 0.38 & 0.02 & 0.49 & 25 & 450 & 1221.6 \\
\hline 75 & 0.40 & 0.06 & 0.03 & 0.51 & 40 & 350 & 4243.8 \\
\hline 76 & 0.30 & 0.20 & 0.02 & 0.49 & 40 & 350 & 4243.8 \\
\hline 77 & 0.20 & 0.16 & 0.03 & 0.62 & 40 & 350 & 4243.8 \\
\hline 78 & 0.19 & 0.25 & 0.02 & 0.54 & 25 & 450 & 1447.8 \\
\hline 79 & 0.04 & 0.50 & 0.02 & 0.45 & 40 & 350 & 4243.8 \\
\hline 80 & 0.12 & 0.25 & 0.02 & 0.62 & 40 & 350 & 4243.8 \\
\hline 81 & 0.23 & 0.06 & 0.02 & 0.70 & 25 & 450 & 1091.5 \\
\hline 82 & 0.40 & 0.15 & 0.03 & 0.42 & 25 & 350 & 3144.3 \\
\hline 83 & 0.12 & 0.38 & 0.02 & 0.49 & 40 & 350 & 4243.8 \\
\hline 84 & 0.40 & 0.06 & 0.02 & 0.53 & 25 & 450 & 1382.1 \\
\hline 85 & 0.30 & 0.16 & 0.03 & 0.52 & 40 & 350 & 4243.8 \\
\hline 86 & 0.40 & 0.06 & 0.03 & 0.51 & 25 & 450 & 1293.1 \\
\hline 87 & 0.30 & 0.20 & 0.03 & 0.48 & 40 & 350 & 4243.8 \\
\hline 88 & 0.30 & 0.20 & 0.03 & 0.48 & 40 & 450 & 3308.8 \\
\hline 89 & 0.12 & 0.38 & 0.03 & 0.48 & 25 & 450 & 1238.8 \\
\hline 90 & 0.04 & 0.50 & 0.03 & 0.43 & 25 & 350 & 2900.4 \\
\hline 91 & 0.40 & 0.15 & 0.02 & 0.44 & 25 & 450 & 1486.6 \\
\hline 92 & 0.30 & 0.16 & 0.02 & 0.53 & 40 & 450 & 3066.6 \\
\hline 93 & 0.12 & 0.38 & 0.03 & 0.48 & 25 & 350 & 3149.8 \\
\hline 94 & 0.23 & 0.06 & 0.02 & 0.70 & 25 & 350 & 4243.8 \\
\hline 95 & 0.05 & 0.50 & 0.03 & 0.42 & 40 & 350 & 4243.8 \\
\hline 96 & 0.04 & 0.23 & 0.03 & 0.70 & 40 & 450 & 2622.3 \\
\hline 97 & 0.12 & 0.38 & 0.03 & 0.48 & 40 & 450 & 3344.5 \\
\hline 98 & 0.40 & 0.15 & 0.02 & 0.44 & 40 & 450 & 3943.0 \\
\hline 99 & 0.05 & 0.50 & 0.03 & 0.42 & 25 & 350 & 3164.3 \\
\hline 100 & 0.40 & 0.15 & 0.03 & 0.42 & 40 & 450 & 4296.2 \\
\hline
\end{tabular}

